\title{
OPEN Healthy US population reference values for $C T$ visceral fat measurements and the impact of IV contrast, HU range, and spinal levels
}

\author{
Brian A. Derstine ${ }^{\bowtie}$, Sven A Holcombe, Brian E Ross, Nicholas C Wang, Stewart C Wang \&
} Grace L Su

Measurements of visceral adipose tissue cross-sectional area and radiation attenuation from computed tomography (CT) scans provide useful information about risk and mortality. However, scan protocols vary, encompassing differing vertebra levels and utilizing differing phases of contrast enhancement. Furthermore, fat measurements have been extracted from CT using different Hounsfield Unit (HU) ranges. To our knowledge, there have been no large studies of healthy cohorts that reported reference values for visceral fat area and radiation attenuation at multiple vertebra levels, for different contrast phases, and using different fat HU ranges. Two-phase CT scans from 1,677 healthy, adult kidney donors (age 18-65) between 1999 and 2017, previously studied to determine healthy reference values for skeletal muscle measures, were utilized. Visceral adipose tissue crosssectional area (VFA) and radiation attenuation (VFRA) measures were quantified using axial slices at T10 through L4 vertebra levels. T-tests were used to compare males and females, while paired t-tests were conducted to determine the effect (magnitude and direction) of (a) contrast enhancement and (b) different fat HU ranges on each fat measure at each vertebra level. We report the means, standard deviations, and effect sizes of contrast enhancement and fat HU range. Male and female VFA and VFRA were significantly different at all vertebra levels in both contrast and non-contrast scans. Peak VFA was observed at L4 in females and L2 in males, while peak VFRA was observed at L1 in both females and males. In general, non-contrast scans showed significantly greater VFA and VFRA compared to contrast scans. The average paired difference due to contrast ranged from 1.6 to $-8 \%$ (VFA) and 3.2 to $-3.0 \%$ (VFRA) of the non-contrast value. HU range showed much greater differences in VFA and VFRA than contrast. The average paired differences due to $\mathrm{HU}$ range ranged from -5.3 to $22.2 \%$ (VFA) and -5.9 to $13.6 \%$ (VFRA) in non-contrast scans, and -4.4 to $20.2 \%$ (VFA) and -4.1 to $12.6 \%$ (VFRA) in contrast scans. The -190 to $-30 \mathrm{HU}$ range showed the largest differences in both VFA $(10.8 \%$ to $22.2 \%)$ and VFRA $(7.6 \%$ to $13.6 \%)$ compared to the reference range ( 205 to $-51 \mathrm{HU})$. Incidentally, we found that differences in lung inflation result in very large differences in visceral fat measures, particularly in the thoracic region. We assessed the independent effects of contrast presence and fat $\mathrm{HU}$ ranges on visceral fat cross-sectional area and mean radiation attenuation, finding significant differences particularly between different fat $\mathrm{HU}$ ranges. These results demonstrate that CT measurements of visceral fat area and radiation attenuation are strongly dependent upon contrast presence, fat $\mathrm{HU}$ range, sex, breath cycle, and vertebra level of measurement. We quantified contrast and non-contrast reference values separately for males and females, using different fat $\mathrm{HU}$ ranges, for lumbar and thoracic CT visceral fat measures at multiple vertebra levels in a healthy adult US population.

The amount, distribution, and quality of fat in the core region of the body have significant clinical implications ${ }^{1,2}$. Visceral adiposity has been associated more accurately with cardiometabolic abnormalities than standard body 


\begin{tabular}{|c|c|c|c|c|c|c|c|}
\hline & \multicolumn{3}{|c|}{ Female } & \multicolumn{3}{|c|}{ Male } & \multirow[b]{2}{*}{$P$} \\
\hline & n & Mean & SD & n & Mean & SD & \\
\hline Age (yr) & 1042 & 41.90 & 11.68 & 635 & 39.65 & 11.69 & $<0.001$ \\
\hline Height (m) & 1042 & 1.64 & 0.06 & 635 & 1.78 & 0.07 & $<0.001$ \\
\hline Weight (kg) & 1042 & 72.40 & 14.02 & 635 & 88.03 & 15.01 & $<0.001$ \\
\hline BMI $\left(\mathbf{k g} / \mathbf{m}^{2}\right)$ & 1042 & 26.94 & 4.90 & 635 & 27.60 & 4.11 & 0.003 \\
\hline Underweight & 11 & $1.1 \%$ & & 0 & $0.0 \%$ & & \\
\hline Normal & 394 & 37.8 & & 168 & $26.5 \%$ & & \\
\hline Overweight & 360 & $34.5 \%$ & & 318 & $50.1 \%$ & & \\
\hline Obese class I & 207 & $19.9 \%$ & & 110 & $17.3 \%$ & & \\
\hline Obese class II & 58 & $5.6 \%$ & & 37 & $5.8 \%$ & & \\
\hline Obese class III & 12 & $1.2 \%$ & & 2 & $0.3 \%$ & & \\
\hline Donor & & & & & & & 0.816 \\
\hline No & 365 & $35.0 \%$ & & 219 & $34.5 \%$ & & \\
\hline Yes & 677 & $65.0 \%$ & & 416 & $65.5 \%$ & & \\
\hline Race & & & & & & & 0.794 \\
\hline African American & 100 & $9.6 \%$ & & 53 & $8.3 \%$ & & \\
\hline Caucasian & 650 & $62.4 \%$ & & 394 & $62.0 \%$ & & \\
\hline Not Reported & 251 & $24.1 \%$ & & 163 & $25.7 \%$ & & \\
\hline Other & 41 & $3.9 \%$ & & 25 & $3.9 \%$ & & \\
\hline
\end{tabular}

Table 1. Cohort summary demographics split by sex. Donor and race proportion $P$-value from Chi-squared test, all others from t-test comparing Females to Males.

measurements such as body mass index $(\mathrm{BMI})^{3}$. Both the area and radiation attenuation of visceral fat have been associated with important clinical outcomes including mortality ${ }^{2}$. In the Framingham Heart Study, decreasing abdominal visceral fat attenuation was associated with worse cardiovascular outcome and greater cardiometabolic risk ${ }^{2,4}$, while increased pericardial and intrathoracic fat was associated with decreased adiponectin and increased metabolic risk ${ }^{5}$. In patients with liver disease, higher visceral fat attenuation has been associated with higher mortality in patients with chronic liver disease and hepatocellular carcinoma ${ }^{6-8}$.

Visceral fat measurements can be inferred from methodologies such as anthropometry, dual energy X-ray absorptiometry (DXA), and bioelectrical impedance analysis (BIA). Higher-cost methods such as magnetic resonance $(\mathrm{MR})$ and computed tomography $(\mathrm{CT})$ can definitively delineate visceral from subcutaneous fat, however, MR is more expensive, slower, and less common than CT. Therefore, using existing CT scans acquired for clinical indications can be a convenient source of detailed body composition information without additional cost or risk of radiation. However, routine CTs have differential protocols, including differences in contrast administration, and different ranges of Hounsfield Unit (HU) values have been used to define fat pixels, both of which may affect fat measurements.

A few studies have investigated the effect of contrast phase on CT visceral fat measurement in clinical cohorts, generally reporting that VFA is higher in non-contrast compared contrast phase scans, though effect sizes varied widely and different fat $\mathrm{HU}$ ranges were used ${ }^{9-14}$.

The definition of visceral fat measured from CT depends upon the HU range used to define and extract fat pixels from imaging. Commonly used HU ranges include -150 to $-50 \mathrm{HU}^{9-11},-195$ to $-45 \mathrm{HU}^{15-17},-190$ to $-30 \mathrm{HU}^{18-21}$, and -250 to $-50 \mathrm{HU}^{22}$. We used -205 to $-51 \mathrm{HU}$ based on the adult fat threshold preset in Materialize Mimics software (version 17.0).

Studies recommend measuring visceral fat at the L4-L5 level to maximize correlation between axial fat areas and whole body fat volumes ${ }^{18,19,21,23}$. However, the L4-L5 level is not available in all clinical CT scan protocols.

Previous work has reported healthy reference values for skeletal muscle measures using similarly large cohorts of kidney donor candidates ${ }^{24-26}$.

To our knowledge, no study has reported sex-specific, contrast and non-contrast reference values for visceral fat area and radiation attenuation in a large, healthy, US adult cohort, utilizing different fat HU ranges. The aim of this study is to quantify the effect of contrast and fat HU range on fat measurements and report reference values. Understanding these effects on visceral fat area and density would allow us to better leverage the important information that is present in CT scans performed for clinical indications.

\section{Results}

Cohort summary. The majority of subjects (1093, 65.2\%) eventually donated a kidney while the remainder $(584,34.8 \%)$ had no record of donation. Comparing females to males (F/M), there was no significant difference in donor proportion $(65.0 / 65.5 \%, P=0.816)$ or race $(62.4 / 62.0 \%$ Caucasian, $9.6 / 8.3 \%$ African American, $3.9 / 3.9 \%$ Other, $P=0.794)$ (Table 1$)$. Females were older $(41.9 / 39.65 y r, P<0.001)$, shorter $(1.64 / 1.78 \mathrm{~m}, P<$ $0.001)$ and weighed less $(72.4 / 88.0 \mathrm{~kg}, P<0.001)$, and had slightly lower BMI $\left(26.9 / 27.6 \mathrm{~kg} / \mathrm{m}^{2}, 2=0.003\right) \mathrm{com}-$ pared to males. 


\begin{tabular}{|c|c|c|c|c|c|c|c|c|}
\hline & \multicolumn{3}{|c|}{ Female } & \multicolumn{3}{|c|}{ Male } \\
\hline & & & $\mathbf{n}$ & Mean & SD & $\mathbf{n}$ & Mean & SD \\
\hline \multirow{14}{*}{ VFA $\left(\mathrm{cm}^{2}\right)$} & \multirow{7}{*}{ Contrast } & T10 & 283 & 52.1 & 28.7 & 165 & 98.2 & 55.7 \\
\hline & & T11 & 814 & 51.6 & 35.5 & 494 & 107.6 & 68.0 \\
\hline & & T12 & 1024 & 58.6 & 44.1 & 625 & 123.9 & 79.6 \\
\hline & & L1 & 1040 & 69.6 & 49.8 & 635 & 140.3 & 85.6 \\
\hline & & L2 & 1036 & 74.3 & 50.5 & 633 & 141.4 & 85.3 \\
\hline & & L3 & 1025 & 77.0 & 50.9 & 627 & 131.9 & 78.7 \\
\hline & & L4 & 966 & 79.8 & 45.6 & 580 & 116.3 & 63.4 \\
\hline & \multirow{7}{*}{ Non-contrast } & T10 & 283 & 55.6 & 28.8 & 165 & 97.1 & 52.6 \\
\hline & & T11 & 814 & 53.9 & 35.5 & 494 & 109.6 & 69.0 \\
\hline & & T12 & 1024 & 60.7 & 45.7 & 625 & 127.6 & 82.3 \\
\hline & & L1 & 1040 & 71.7 & 52.1 & 635 & 145.0 & 89.1 \\
\hline & & L2 & 1036 & 77.9 & 53.7 & 633 & 148.0 & 89.7 \\
\hline & & L3 & 1025 & \begin{tabular}{|l|l|}
81.9 \\
\end{tabular} & 53.7 & 627 & 141.1 & 82.5 \\
\hline & & L4 & 966 & 84.9 & 48.3 & 580 & 123.5 & 66.3 \\
\hline \multirow{14}{*}{ VFRA $(H U)$} & \multirow{7}{*}{ Contrast } & T10 & 283 & -97.0 & 5.2 & 165 & -99.9 & 4.8 \\
\hline & & T11 & 814 & -94.7 & 5.2 & 494 & -98.3 & 5.4 \\
\hline & & T12 & 1024 & -92.4 & 5.9 & 625 & -96.2 & 5.8 \\
\hline & & $\mathrm{L} 1$ & 1040 & -92.2 & 6.4 & 635 & -95.5 & 6.3 \\
\hline & & L2 & 1036 & -93.4 & 6.4 & 633 & -96.6 & 6.7 \\
\hline & & L3 & 1025 & -94.8 & 6.1 & 627 & -97.8 & 6.4 \\
\hline & & L4 & 966 & -95.3 & 5.4 & 580 & -96.7 & 5.9 \\
\hline & \multirow{7}{*}{ Non-contrast } & T10 & 283 & -98.1 & 5.2 & 165 & -101.0 & 4.5 \\
\hline & & T11 & 814 & -96.0 & 5.9 & 494 & -98.8 & 5.2 \\
\hline & & T12 & 1024 & -92.8 & 5.9 & 625 & -95.9 & 5.4 \\
\hline & & L1 & 1040 & -90.8 & 6.2 & 635 & -94.3 & 6.1 \\
\hline & & L2 & 1036 & -91.9 & 6.1 & 633 & -95.4 & 6.4 \\
\hline & & L3 & 1025 & -93.5 & 5.8 & 627 & -96.5 & 6.4 \\
\hline & & L4 & 966 & -93.8 & 5.1 & 580 & -95.2 & 5.8 \\
\hline
\end{tabular}

Table 2. Male and Female mean and standard deviation for T10-L4 VFA and VFRA split by contrast status, vertebra level. All measures use the -205 to $-51 \mathrm{HU}$ reference range.

Reference values. Sex-specific mean and standard deviation (s.d.) healthy, adult reference values for VFA and VFRA at T10-L4 vertebra levels are reported separately for contrast and non-contrast phase for the reference -205 to $-50 \mathrm{HU}$ range (Table 2). Peak VFA (contrast/noncontrast) was observed at L4 in females $\left(79.8 / 84.9 \mathrm{~cm}^{2}\right)$ and L2 in males $\left(141.4 / 148 \mathrm{~cm}^{2}\right)$ while trough VFA was observed at T11 in females $(51.6 / 53.9$ $\left.\mathrm{cm}^{2}\right)$ and T10 in males $\left(98.2 / 97.1 \mathrm{~cm}^{2}\right)$. Peak VFRA was observed at L1 in both females $(-92.2 /-90.8 \mathrm{HU})$ and males $(-95.5 /-94.3 \mathrm{HU})$ while trough VFRA was observed at T10 in both females $(-97.0 /-98.1 \mathrm{HU})$ and males (-99.9/- 101.0HU).

Contrast versus non-contrast. VFA was greater in non-contrast versus contrast scans for all mean paired differences, except for those at T10 in males. In males at T10 the differences were not significantly different for all $\mathrm{HU}$ ranges. Across all vertebra levels and all $\mathrm{HU}$ ranges, mean paired differences ranged from -3.0 to $-8.1 \%$ in women and 1.6 to $-8.0 \%$ in men, expressed as percent of the mean non-contrast VFA (Table 3).

The -190 to $-30 \mathrm{HU}$ range showed the largest paired differences in VFA between contrast and non-contrast scans, followed by -150 to $-50 \mathrm{HU},-250$ to $-50 \mathrm{HU},-195$ to $-45 \mathrm{HU}$, and finally -205 to $-51 \mathrm{HU}$. The largest differences between contrast and non-contrast were found at L3, L4, and T10 in females and at L3 and $\mathrm{L} 4$ in males, across all HU ranges.

VFRA was greater in non-contrast versus contrast scans for all mean paired differences between L1 and L4 in males and females, however, for T10-T12 the results differed by HU range and sex (Table 4).

For both VFA and VFRA, Bland-Altman plots of agreement demonstrated proportional bias at all vertebra levels and in all $\mathrm{HU}$ ranges; as the mean value increased there was a trend toward greater differences and the variance of the differences increased (Figs. 1 and 2). For VFA, the trend was positive at T10, neutral/negative at T11, and negative for T12 through L4. For VFRA, trends varied by vertebra level and HU range. Comparing HU ranges, the variance of VFA was fairly consistent across ranges, however, the variance of VFRA increased as the HU range increased. 


\begin{tabular}{|c|c|c|c|c|c|c|c|c|c|c|c|c|}
\hline & & \multirow[b]{2}{*}{ HU range } & \multicolumn{5}{|c|}{ Female } & \multicolumn{5}{|c|}{ Male } \\
\hline & & & $\mathbf{n}$ & $\mu_{n c}$ & $\mu_{d}$ & $\mu_{d} / \mu_{n c}(\%)$ & $P$ & $\mathbf{n}$ & $\mu_{n c}$ & $\mu_{d}$ & $\mu_{d} / \mu_{n c}(\%)$ & $P$ \\
\hline \multirow{35}{*}{ VFA $\left(\mathrm{cm}^{2}\right)$} & \multirow{5}{*}{$\mathrm{T} 10$} & -150 to $-50 \mathrm{HU}$ & 283 & 52.7 & -2.8 & -5.6 & $<0.001$ & 165 & 92.8 & 1.5 & 1.6 & 0.300 \\
\hline & & -190 to $-30 \mathrm{HU}$ & 283 & 67.5 & -4.9 & -7.8 & $<0.001$ & 165 & 113.6 & -0.8 & -0.7 & 0.576 \\
\hline & & -195 to $-45 \mathrm{HU}$ & 283 & 58.6 & -3.7 & -6.7 & $<0.001$ & 165 & 101.3 & 0.8 & 0.8 & 0.563 \\
\hline & & -205 to $-51 \mathrm{HU}$ & 283 & 55.6 & -3.5 & -6.7 & $<0.001$ & 165 & 97.1 & 1.1 & 1.1 & 0.431 \\
\hline & & -250 to $-50 \mathrm{HU}$ & 283 & 58.4 & -4.4 & -8.1 & $<0.001$ & 165 & 100.6 & 0.0 & -0.0 & 0.976 \\
\hline & \multirow{5}{*}{ T11 } & -150 to $-50 \mathrm{HU}$ & 814 & 51.9 & -2.0 & -4.0 & $<0.001$ & 494 & 106.3 & -2.2 & -2.1 & 0.004 \\
\hline & & -190 to $-30 \mathrm{HU}$ & 814 & 65.8 & -4.0 & -6.4 & $<0.001$ & 494 & 126.9 & -4.3 & -3.5 & $<0.001$ \\
\hline & & -195 to $-45 \mathrm{HU}$ & 814 & 57.0 & -2.6 & -4.8 & $<0.001$ & 494 & 114.2 & -2.4 & -2.2 & 0.002 \\
\hline & & -205 to $-51 \mathrm{HU}$ & 814 & 53.9 & -2.4 & -4.6 & $<0.001$ & 494 & 109.6 & -2.0 & -1.9 & 0.008 \\
\hline & & -250 to $-50 \mathrm{HU}$ & 814 & 56.0 & -3.0 & -5.8 & $<0.001$ & 494 & 112.4 & -2.9 & -2.6 & $<0.001$ \\
\hline & \multirow{5}{*}{$\mathrm{T} 12$} & -150 to $-50 \mathrm{HU}$ & 1024 & 59.5 & -2.3 & -4.0 & $<0.001$ & 625 & 125.4 & -4.7 & -3.9 & $<0.001$ \\
\hline & & -190 to $-30 \mathrm{HU}$ & 1024 & 74.2 & -4.2 & -6.0 & $<0.001$ & 625 & 147.3 & -6.5 & -4.6 & $<0.001$ \\
\hline & & -195 to $-45 \mathrm{HU}$ & 1024 & 64.3 & -2.5 & -4.1 & $<0.001$ & 625 & 133.0 & -4.3 & -3.3 & $<0.001$ \\
\hline & & -205 to $-51 \mathrm{HU}$ & 1024 & 60.7 & -2.2 & -3.7 & $<0.001$ & 625 & 127.6 & -3.8 & -3.0 & $<0.001$ \\
\hline & & -250 to $-50 \mathrm{HU}$ & 1024 & 62.3 & -2.6 & -4.3 & $<0.001$ & 625 & 129.9 & -4.3 & -3.4 & $<0.001$ \\
\hline & \multirow{5}{*}{ L1 } & -150 to $-50 \mathrm{HU}$ & 1040 & 70.6 & -2.5 & -3.7 & $<0.001$ & 635 & 143.1 & -5.8 & -4.2 & $<0.001$ \\
\hline & & -190 to $-30 \mathrm{HU}$ & 1040 & 87.3 & -4.7 & -5.6 & $<0.001$ & 635 & 166.5 & -7.9 & -5.0 & $<0.001$ \\
\hline & & -195 to $-45 \mathrm{HU}$ & 1040 & 75.9 & -2.6 & -3.6 & $<0.001$ & 635 & 151.0 & -5.4 & -3.7 & $<0.001$ \\
\hline & & -205 to $-51 \mathrm{HU}$ & 1040 & 71.7 & -2.1 & -3.0 & $<0.001$ & 635 & 145.0 & -4.7 & -3.3 & $<0.001$ \\
\hline & & -250 to $-50 \mathrm{HU}$ & 1040 & 73.2 & -2.4 & -3.4 & $<0.001$ & 635 & 147.2 & -5.1 & -3.6 & $<0.001$ \\
\hline & \multirow{5}{*}{ L2 } & -150 to $-50 \mathrm{HU}$ & 1036 & 76.6 & -4.1 & -5.7 & $<0.001$ & 633 & 145.9 & -7.8 & -5.6 & $<0.001$ \\
\hline & & -190 to $-30 \mathrm{HU}$ & 1036 & 93.2 & -6.1 & -7.0 & $<0.001$ & 633 & 167.4 & -9.5 & -6.0 & $<0.001$ \\
\hline & & -195 to $-45 \mathrm{HU}$ & 1036 & 82.1 & -4.2 & -5.3 & $<0.001$ & 633 & 153.4 & -7.2 & -4.9 & $<0.001$ \\
\hline & & -205 to $-51 \mathrm{HU}$ & 1036 & 77.9 & -3.6 & -4.8 & $<0.001$ & 633 & 148.0 & -6.6 & -4.6 & $<0.001$ \\
\hline & & -250 to $-50 \mathrm{HU}$ & 1036 & 79.6 & -3.9 & -5.2 & $<0.001$ & 633 & 150.0 & -7.0 & -4.9 & $<0.001$ \\
\hline & \multirow{5}{*}{ L3 } & -150 to $-50 \mathrm{HU}$ & 1025 & 80.5 & -5.5 & -7.3 & $<0.001$ & 627 & 139.2 & -10.3 & -8.0 & $<0.001$ \\
\hline & & -190 to $-30 \mathrm{HU}$ & 1025 & 95.9 & -7.0 & -7.9 & $<0.001$ & 627 & 157.8 & -11.7 & -8.0 & $<0.001$ \\
\hline & & -195 to $-45 \mathrm{HU}$ & 1025 & 85.7 & -5.4 & -6.7 & $<0.001$ & 627 & 145.7 & -9.8 & -7.2 & $<0.001$ \\
\hline & & -205 to $-51 \mathrm{HU}$ & 1025 & 81.9 & -4.9 & -6.4 & $<0.001$ & 627 & 141.1 & -9.2 & -7.0 & $<0.001$ \\
\hline & & -250 to $-50 \mathrm{HU}$ & 1025 & 83.5 & -5.2 & -6.7 & $<0.001$ & 627 & 142.9 & -9.6 & -7.2 & $<0.001$ \\
\hline & \multirow{5}{*}{$\mathrm{L} 4$} & -150 to $-50 \mathrm{HU}$ & 966 & 83.5 & -5.7 & -7.3 & $<0.001$ & 580 & 122.0 & -8.0 & -7.0 & $<0.001$ \\
\hline & & -190 to $-30 \mathrm{HU}$ & 966 & 100.0 & -7.4 & -7.9 & $<0.001$ & 580 & 140.8 & -9.8 & -7.5 & $<0.001$ \\
\hline & & -195 to $-45 \mathrm{HU}$ & 966 & 89.0 & -5.6 & -6.7 & $<0.001$ & 580 & 128.3 & -7.8 & -6.5 & $<0.001$ \\
\hline & & -205 to $-51 \mathrm{HU}$ & 966 & 84.9 & -5.1 & -6.4 & $<0.001$ & 580 & 123.5 & -7.2 & -6.2 & $<0.001$ \\
\hline & & -250 to $-50 \mathrm{HU}$ & 966 & 86.5 & -5.4 & -6.7 & $<0.001$ & 580 & 125.3 & -7.6 & -6.4 & $<0.001$ \\
\hline
\end{tabular}

Table 3. Mean VFA paired differences (contrast-non-contrast) raw $\left(\mu_{d}\right)$ and as percent of overall mean non-contrast value $\left(\mu_{n c}\right) . P$-values from paired t-test for T10-L4 with null hypothesis $\mu_{d}=0$. Negative values indicate contrast value lower than non- contrast value, on average. $P$-values $<0.01$ in bold.

Fat HU range. Compared to the -205 to $-50 \mathrm{HU}$ reference range, VFA was lower for the -150 to -50 HU range, and higher for all other ranges at all vertebra levels in both sexes and for both contrast and noncontrast scans (Tables 5 and 6). The largest differences were observed with the -190 to -30 HU range, which ranged from $15.4 \%$ (L3) to $20.2 \%$ (T10) in females and from $10.8 \%$ (L3) to $14.8 \%$ (T10) in males for contrast scans (Table 5), and from $17.1 \%$ (L3) to $22.2 \%$ (T12) in females and from $11.8 \%$ (L3) to $17.0 \%$ (T10) in males for non-contrast scans (Table 6). The -195 to $-45 \mathrm{HU}$ range showed the second largest (positive) differences, followed by the -150 to $-50 \mathrm{HU}$ (negative), and finally the -250 to $-50 \mathrm{HU}$ range (positive) in both contrast and non-contrast scans.

Compared to the -205 to $-50 \mathrm{HU}$ reference range, VFRA was lower for the -250 to $-50 \mathrm{HU}$ range, and higher for all other ranges at all vertebra levels in both sexes and for both contrast and non-contrast scans (Tables 7 and 8). The largest differences were observed with the -190 to $-30 \mathrm{HU}$ range, which ranged from 


\begin{tabular}{|c|c|c|c|c|c|c|c|c|c|c|c|c|}
\hline & & \multirow[b]{2}{*}{ HU range } & \multicolumn{5}{|c|}{ Female } & \multicolumn{5}{|c|}{ Male } \\
\hline & & & $\mathrm{n}$ & $\mu_{n c}$ & $\mu_{d}$ & $\mu_{d} /\left|\mu_{n c}\right|(\%)$ & $P$ & $\mathrm{n}$ & $\mu_{n c}$ & $\mu_{d}$ & $\mu_{d} /\left|\mu_{n c}\right|(\%)$ & $P$ \\
\hline \multirow{35}{*}{ VFRA $(H U)$} & \multirow{5}{*}{ T10 } & -150 to $-50 \mathrm{HU}$ & 283 & -90.7 & -0.1 & -0.1 & 0.551 & 165 & -94.7 & -0.1 & -0.1 & 0.600 \\
\hline & & -190 to $-30 \mathrm{HU}$ & 283 & -84.8 & 0.0 & -0.0 & 0.946 & 165 & -89.1 & -0.7 & -0.7 & 0.026 \\
\hline & & -195 to $-45 \mathrm{HU}$ & 283 & -93.6 & 0.6 & 0.7 & 0.014 & 165 & -97.1 & 0.4 & 0.4 & 0.236 \\
\hline & & -205 to $-51 \mathrm{HU}$ & 283 & -98.1 & 1.1 & 1.1 & $<0.001$ & 165 & -101.0 & 1.0 & 1.0 & 0.004 \\
\hline & & -250 to $-50 \mathrm{HU}$ & 283 & -103.8 & 2.8 & 2.8 & $<0.001$ & 165 & -105.5 & 2.8 & 2.7 & $<0.001$ \\
\hline & \multirow{5}{*}{ T11 } & -150 to $-50 \mathrm{HU}$ & 814 & -89.7 & -0.1 & -0.1 & 0.260 & 494 & -93.8 & -0.2 & -0.2 & 0.107 \\
\hline & & -190 to $-30 \mathrm{HU}$ & 814 & -82.9 & -0.2 & -0.2 & 0.289 & 494 & -88.0 & -0.8 & -0.9 & $<0.001$ \\
\hline & & -195 to $-45 \mathrm{HU}$ & 814 & -91.7 & 0.7 & 0.8 & $<0.001$ & 494 & -95.3 & \begin{tabular}{|l|}
0.0 \\
\end{tabular} & -0.0 & 0.886 \\
\hline & & -205 to $-51 \mathrm{HU}$ & 814 & -96.0 & 1.3 & 1.4 & $<0.001$ & 494 & -98.8 & 0.4 & 0.4 & 0.032 \\
\hline & & -250 to $-50 \mathrm{HU}$ & 814 & -100.8 & 3.1 & 3.2 & $<0.001$ & 494 & -102.2 & 1.7 & 1.7 & $<0.001$ \\
\hline & \multirow{5}{*}{$\mathrm{T} 12$} & -150 to $-50 \mathrm{HU}$ & 1024 & -88.2 & -0.5 & -0.5 & $<0.001$ & 625 & -92.3 & -0.4 & -0.5 & $<0.001$ \\
\hline & & -190 to $-30 \mathrm{HU}$ & 1024 & -80.3 & -1.1 & -1.3 & $<0.001$ & 625 & -85.9 & -1.3 & -1.5 & $<0.001$ \\
\hline & & -195 to $-45 \mathrm{HU}$ & 1024 & -88.8 & -0.1 & -0.1 & 0.299 & 625 & -92.8 & -0.7 & -0.7 & $<0.001$ \\
\hline & & -205 to $-51 \mathrm{HU}$ & 1024 & -92.8 & 0.3 & 0.4 & 0.018 & 625 & -95.9 & -0.4 & -0.4 & 0.016 \\
\hline & & -250 to $-50 \mathrm{HU}$ & 1024 & -95.8 & 1.6 & \begin{tabular}{|l|}
1.7 \\
\end{tabular} & $<0.001$ & 625 & -98.0 & 0.4 & 0.4 & 0.056 \\
\hline & \multirow{5}{*}{ L1 } & -150 to $-50 \mathrm{HU}$ & 1040 & -87.3 & -1.4 & -1.6 & $<0.001$ & 635 & -91.7 & -0.9 & -1.0 & $<0.001$ \\
\hline & & -190 to $-30 \mathrm{HU}$ & 1040 & -79.2 & -2.4 & -3.0 & $<0.001$ & 635 & -85.2 & -1.9 & -2.2 & $<0.001$ \\
\hline & & -195 to $-45 \mathrm{HU}$ & 1040 & -87.2 & -1.7 & -1.9 & $<0.001$ & 635 & -91.6 & -1.4 & -1.5 & $<0.001$ \\
\hline & & -205 to $-51 \mathrm{HU}$ & 1040 & -90.8 & -1.4 & -1.5 & $<0.001$ & 635 & -94.3 & -1.2 & -1.2 & $<0.001$ \\
\hline & & -250 to $-50 \mathrm{HU}$ & 1040 & -92.8 & -0.7 & -0.7 & $<0.001$ & 635 & -95.7 & -0.7 & -0.8 & $<0.001$ \\
\hline & \multirow{5}{*}{ L2 } & -150 to $-50 \mathrm{HU}$ & 1036 & -88.4 & -1.5 & -1.6 & $<0.001$ & 633 & -92.8 & -0.8 & -0.9 & $<0.001$ \\
\hline & & -190 to $-30 \mathrm{HU}$ & 1036 & -80.9 & -2.4 & -2.9 & $<0.001$ & 633 & -86.9 & -1.9 & -2.1 & $<0.001$ \\
\hline & & -195 to $-45 \mathrm{HU}$ & 1036 & -88.5 & -1.8 & -1.9 & $<0.001$ & 633 & -92.8 & -1.3 & -1.4 & $<0.001$ \\
\hline & & -205 to $-51 \mathrm{HU}$ & 1036 & -91.9 & -1.5 & -1.6 & $<0.001$ & 633 & -95.4 & -1.2 & -1.2 & $<0.001$ \\
\hline & & -250 to $-50 \mathrm{HU}$ & 1036 & -93.9 & -0.9 & -1.0 & $<0.001$ & 633 & -96.7 & -0.8 & -0.8 & $<0.001$ \\
\hline & \multirow{5}{*}{ L3 } & -150 to $-50 \mathrm{HU}$ & 1025 & -90.1 & -1.2 & -1.3 & $<0.001$ & 627 & -94.1 & -0.9 & -0.9 & $<0.001$ \\
\hline & & -190 to $-30 \mathrm{HU}$ & 1025 & -83.3 & -1.9 & -2.3 & $<0.001$ & 627 & -88.6 & -1.8 & -1.9 & $<0.001$ \\
\hline & & -195 to $-45 \mathrm{HU}$ & 1025 & -90.4 & -1.5 & -1.6 & $<0.001$ & 627 & -94.1 & -1.4 & -1.5 & $<0.001$ \\
\hline & & -205 to $-51 \mathrm{HU}$ & 1025 & -93.5 & -1.3 & -1.3 & $<0.001$ & 627 & -96.5 & -1.3 & -1.3 & $<0.001$ \\
\hline & & -250 to $-50 \mathrm{HU}$ & 1025 & -95.5 & -0.7 & -0.8 & $<0.001$ & 627 & -97.7 & -1.0 & -1.0 & $<0.001$ \\
\hline & \multirow{5}{*}{$\mathrm{L} 4$} & -150 to $-50 \mathrm{HU}$ & 966 & -90.7 & -1.3 & -1.4 & $<0.001$ & 580 & -92.9 & -1.3 & -1.4 & $<0.001$ \\
\hline & & -190 to $-30 \mathrm{HU}$ & 966 & -83.8 & -2.2 & -2.5 & $<0.001$ & 580 & -86.9 & -2.1 & -2.4 & $<0.001$ \\
\hline & & -195 to $-45 \mathrm{HU}$ & 966 & -90.7 & -1.7 & -1.9 & $<0.001$ & 580 & -92.7 & -1.7 & -1.8 & $<0.001$ \\
\hline & & -205 to $-51 \mathrm{HU}$ & 966 & -93.8 & -1.5 & -1.6 & $<0.001$ & 580 & -95.2 & -1.6 & -1.6 & $<0.001$ \\
\hline & & -250 to $-50 \mathrm{HU}$ & 966 & -95.4 & -1.1 & -1.1 & $<0.001$ & 580 & -96.2 & -1.2 & -1.2 & $<0.001$ \\
\hline
\end{tabular}

Table 4. Mean VFRA paired differences (contrast-non-contrast) raw $\left(\mu_{d}\right)$ and as percent of absolute mean non-contrast value $\left(\mu_{d} /\left|\mu_{n c}\right|\right)$. P-values from paired t-test for T10-L4 with null hypothesis $\mu_{d}=0$. Negative values indicate contrast value lower than non-contrast value, on average. $P$-values $<0.01$ in bold.

9.8\% (L4) to $12.6 \%$ (T10) in females and from $7.6 \%$ (L3) to $10.1 \%$ (T10) in males for contrast scans (Table 7), and from $10.6 \%(\mathrm{~L} 4)$ to $13.6 \%$ (T10, T11) in females and from $8.2 \%$ (L3) to $11.7 \%$ (T10) in males for non-contrast scans (Table 8 ). The -150 to $-50 \mathrm{HU}$ range showed the second largest (positive) differences, followed by the -195 to $-45 \mathrm{HU}$ range (positive), and finally the -250 to $-50 \mathrm{HU}$ range (negative) in both contrast and noncontrast scans.

Outlier investigation. Individuals with paired differences greater than $4 \mathrm{s.d}$. above/below the mean difference were identified and investigated individually as possible outliers. These pairs displayed distinct differences in lung inflation, resulting in vertical shift of organ locations and large differences in axial visceral non-muscular contents between the two phases of scan. Differences were more visually apparent at the thoracic levels where 


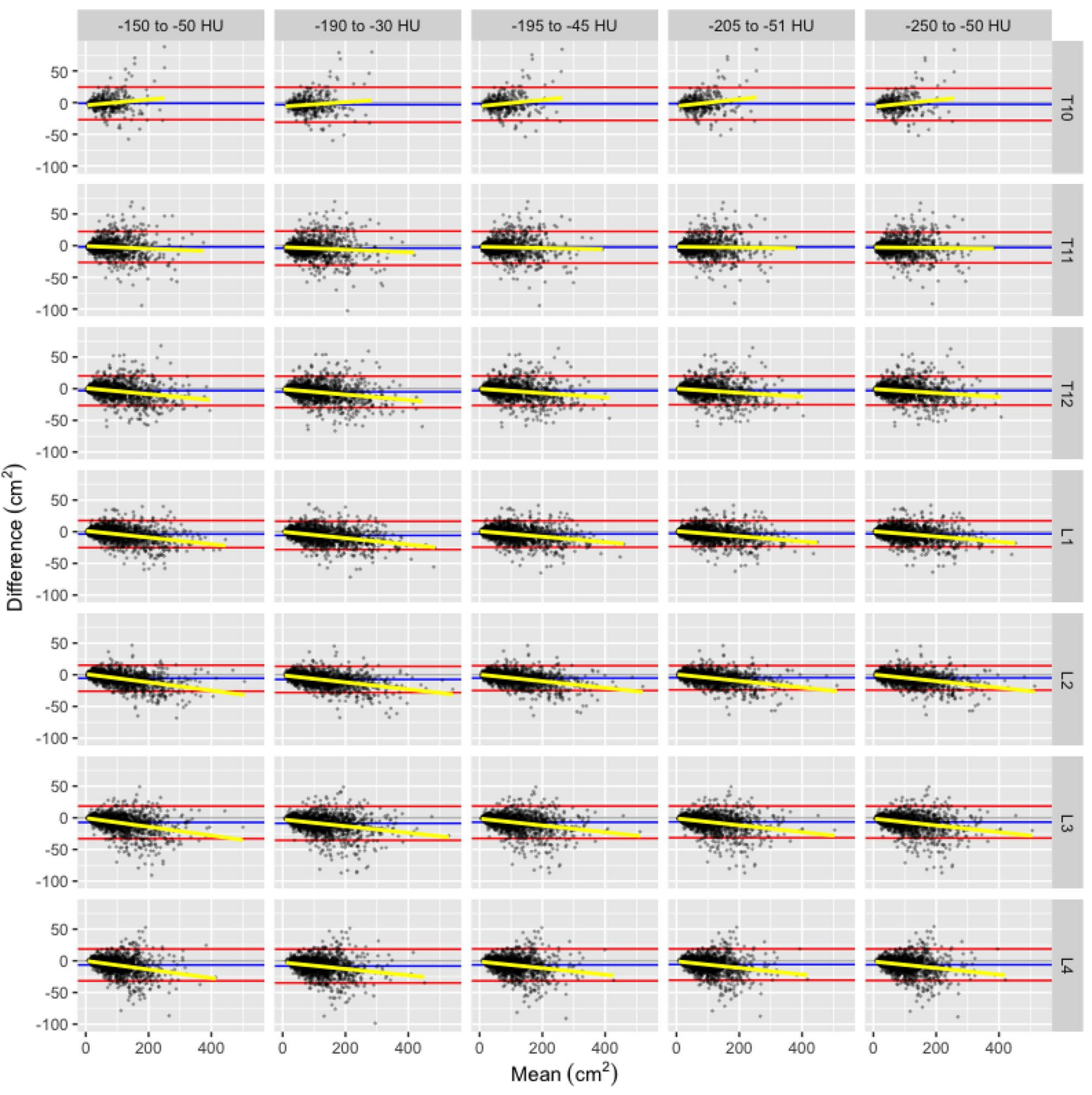

Figure 1. Bland-Altman plot of VFA $\left(\mathrm{cm}^{2}\right)$ by vertebra number, and HU range showing each observation (black point), mean (blue line) and 1.96 standard deviations (red lines) of the paired differences (contrast-noncontrast), linear best-fit regression (yellow line).

lung air was directly observable, and less apparent in the lumbar region where differences were due to more subtle shifts in major organs including liver, kidney, spleen, and bowel (Fig. 3).

\section{Discussion}

Both the presence of intravenous contrast and the particular HU range used to define visceral fat pixels affected measurements of visceral fat cross-sectional area and mean radiation attenuation on CT.

Analysis of contrast versus non-contrast scans showed that VFA was higher in non-contrast scans compared to contrast scans, whereas VFRA was lower in contrast scans compared to non-contrast scans. The difference in 


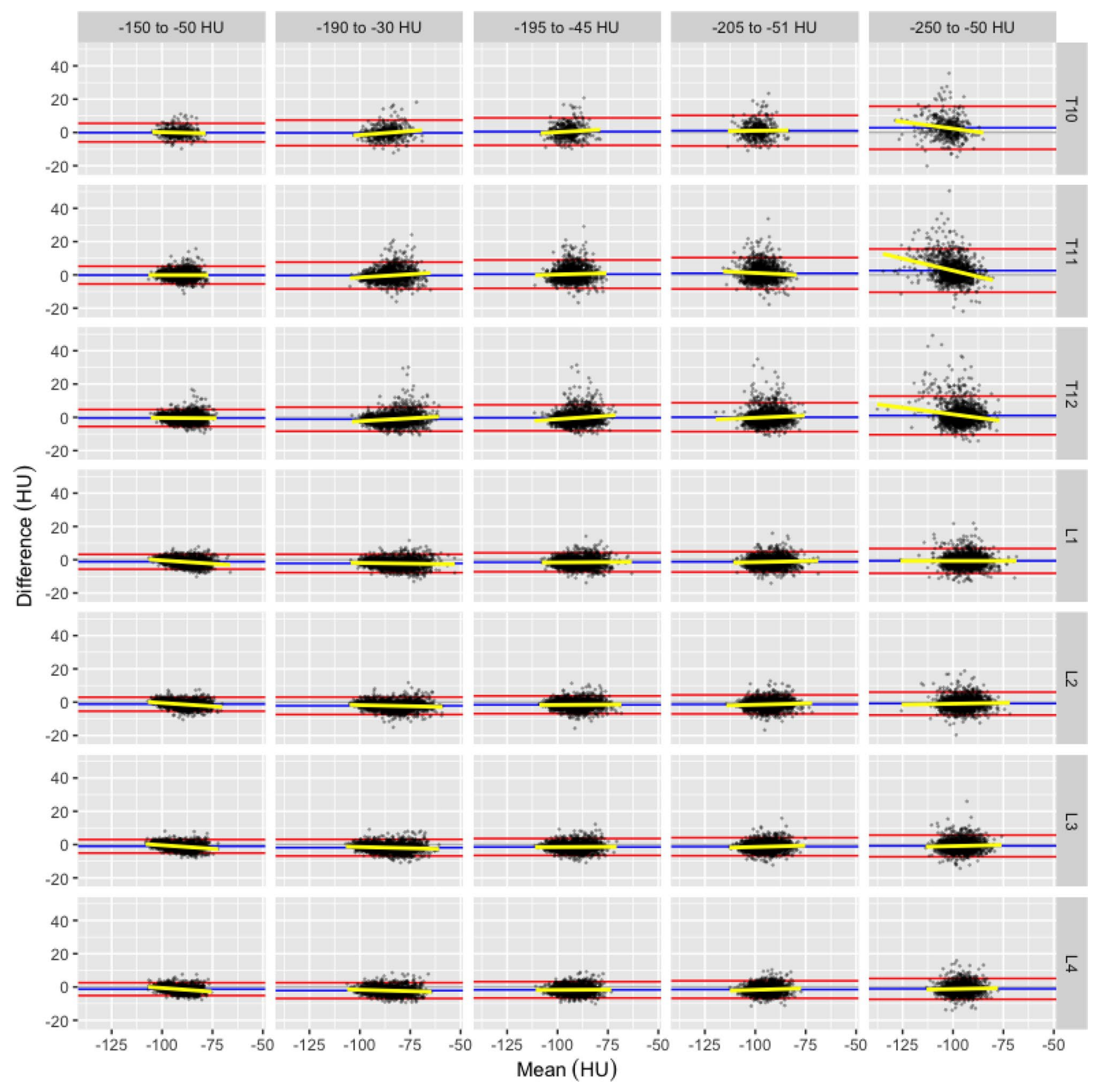

Figure 2. Bland-Altman plot of VFRA (HU) by vertebra number, and HU range showing each observation (black point), mean (blue line) and 1.96 standard deviations (red lines) of the paired differences (contrast-noncontrast), linear best-fit regression (yellow line).

HU was in general quite close to zero, however, Bland-Altman plots demonstrated proportional bias-differences increasing with the mean value-particularly in VFA measurements. The differences due to contrast increased as the area or density of visceral fat increased. Thus, patients with greater visceral fat or greater fat density had greater measurement differences between scans with and without contrast. Therefore, to fairly compare fat measurements for patients with low and high visceral fat, contrast and non-contrast scans should not be mixed within the same study.

Additionally, measurement differences due to HU range were much greater than those due to contrast. In particular, the HU range of - 190 to -30 showed the greatest differences in both VFA and VFRA. This range 


\begin{tabular}{|c|c|c|c|c|c|c|c|c|c|c|c|c|}
\hline & \multirow[b]{2}{*}{ HU range } & \multicolumn{5}{|c|}{ Female } & \multicolumn{5}{|c|}{ Male } \\
\hline & & & $\mathrm{n}$ & $\mu_{r}$ & $\mu_{d}$ & $\mu_{d} \cdot \mu_{r}$ & $P$ & $\mathrm{n}$ & $\mu_{r}$ & $\mu_{d}$ & $\mu_{d} \cdot \mu_{r}$ & $P$ \\
\hline \multirow{28}{*}{ VFA $\left(\mathrm{cm}^{2}\right)$} & \multirow{4}{*}{$\mathrm{T} 10$} & -150 to $-50 \mathrm{HU}$ & 283 & 52.1 & -2.3 & -4.4 & 0.000 & 165 & 98.2 & -3.9 & -4.0 & 0.000 \\
\hline & & -190 to $-30 \mathrm{HU}$ & 283 & 52.1 & 10.5 & 20.2 & 0.000 & 165 & 98.2 & 14.5 & 14.8 & 0.000 \\
\hline & & -195 to $-45 \mathrm{HU}$ & 283 & 52.1 & 2.8 & 5.3 & 0.000 & 165 & 98.2 & 3.8 & 3.9 & 0.000 \\
\hline & & -250 to $-50 \mathrm{HU}$ & 283 & 52.1 & 1.8 & 3.5 & 0.000 & 165 & 98.2 & 2.3 & 2.4 & 0.000 \\
\hline & \multirow{4}{*}{ T11 } & -150 to $-50 \mathrm{HU}$ & 814 & 51.6 & -1.6 & -3.2 & 0.000 & 494 & 107.6 & -3.5 & -3.2 & 0.000 \\
\hline & & -190 to $-30 \mathrm{HU}$ & 814 & 51.6 & 10.3 & 19.9 & 0.000 & 494 & 107.6 & 15.1 & 14.0 & 0.000 \\
\hline & & -195 to $-45 \mathrm{HU}$ & 814 & 51.6 & 2.8 & 5.4 & 0.000 & 494 & 107.6 & 4.2 & 3.9 & 0.000 \\
\hline & & -250 to $-50 \mathrm{HU}$ & 814 & 51.6 & 1.4 & 2.7 & 0.000 & 494 & 107.6 & 2.0 & 1.8 & 0.000 \\
\hline & \multirow{4}{*}{ T12 } & -150 to $-50 \mathrm{HU}$ & 1024 & 58.6 & -1.3 & -2.3 & 0.000 & 625 & 123.9 & -3.1 & -2.5 & 0.000 \\
\hline & & -190 to $-30 \mathrm{HU}$ & 1024 & 58.6 & 11.5 & 19.6 & 0.000 & 625 & 123.9 & 16.9 & 13.6 & 0.000 \\
\hline & & -195 to $-45 \mathrm{HU}$ & 1024 & 58.6 & 3.2 & 5.5 & 0.000 & 625 & 123.9 & 4.8 & 3.9 & 0.000 \\
\hline & & -250 to $-50 \mathrm{HU}$ & 1024 & 58.6 & 1.2 & 2.0 & 0.000 & 625 & 123.9 & 1.8 & 1.4 & 0.000 \\
\hline & \multirow{4}{*}{ L1 } & -150 to $-50 \mathrm{HU}$ & 1040 & 69.6 & -1.5 & -2.2 & 0.000 & 635 & 140.3 & -3.0 & -2.1 & 0.000 \\
\hline & & -190 to $-30 \mathrm{HU}$ & 1040 & 69.6 & 13.0 & 18.7 & 0.000 & 635 & 140.3 & 18.3 & 13.0 & 0.000 \\
\hline & & -195 to $-45 \mathrm{HU}$ & 1040 & 69.6 & 3.7 & 5.3 & 0.000 & 635 & 140.3 & 5.3 & 3.8 & 0.000 \\
\hline & & -250 to $-50 \mathrm{HU}$ & 1040 & 69.6 & 1.3 & 1.8 & 0.000 & 635 & 140.3 & 1.8 & 1.3 & 0.000 \\
\hline & \multirow{4}{*}{ L2 } & -150 to $-50 \mathrm{HU}$ & 1036 & 74.3 & -1.8 & -2.4 & 0.000 & 633 & 141.4 & -3.2 & -2.3 & 0.000 \\
\hline & & -190 to $-30 \mathrm{HU}$ & 1036 & 74.3 & 12.8 & 17.2 & 0.000 & 633 & 141.4 & 16.5 & 11.7 & 0.000 \\
\hline & & -195 to $-45 \mathrm{HU}$ & 1036 & 74.3 & 3.6 & 4.8 & 0.000 & 633 & 141.4 & 4.8 & 3.4 & 0.000 \\
\hline & & -250 to $-50 \mathrm{HU}$ & 1036 & 74.3 & 1.3 & 1.8 & 0.000 & 633 & 141.4 & 1.7 & 1.2 & 0.000 \\
\hline & \multirow{4}{*}{ L3 } & -150 to $-50 \mathrm{HU}$ & 1025 & 77.0 & -2.0 & -2.6 & 0.000 & 627 & 131.9 & -3.0 & -2.3 & 0.000 \\
\hline & & -190 to $-30 \mathrm{HU}$ & 1025 & 77.0 & 11.9 & 15.4 & 0.000 & 627 & 131.9 & 14.2 & 10.8 & 0.000 \\
\hline & & -195 to $-45 \mathrm{HU}$ & 1025 & 77.0 & 3.3 & 4.3 & 0.000 & 627 & 131.9 & 4.1 & 3.1 & 0.000 \\
\hline & & -250 to $-50 \mathrm{HU}$ & 1025 & 77.0 & 1.3 & 1.7 & 0.000 & 627 & 131.9 & 1.5 & 1.1 & 0.000 \\
\hline & \multirow{4}{*}{ L4 } & -150 to $-50 \mathrm{HU}$ & 966 & 79.8 & -2.0 & -2.5 & 0.000 & 580 & 116.3 & -2.2 & -1.9 & 0.000 \\
\hline & & -190 to $-30 \mathrm{HU}$ & 966 & 79.8 & 12.8 & 16.0 & 0.000 & 580 & 116.3 & 14.7 & 12.6 & 0.000 \\
\hline & & -195 to $-45 \mathrm{HU}$ & 966 & 79.8 & 3.6 & 4.5 & 0.000 & 580 & 116.3 & 4.2 & 3.6 & 0.000 \\
\hline & & -250 to $-50 \mathrm{HU}$ & 966 & 79.8 & 1.3 & 1.7 & 0.000 & 580 & 116.3 & 1.4 & 1.2 & 0.000 \\
\hline
\end{tabular}

Table 5. Contrast scan mean VFA paired differences (comparison range-reference range) raw $\left(\mu_{d}\right)$ and as percent of overall mean reference range value $\left(\mu_{d} / \mu_{r}\right)$. $P$-values from paired t-test for T10-L 4 with null hypothesis $\mu_{d}=0$. Negative values indicate comparison range value lower than reference range value, on average. Reference range is -205 to -51 HU. $P$-values $<0.01$ in bold.

was the only range that includes $\mathrm{HU}$ values greater than - $45 \mathrm{HU}$, suggesting that the large difference was primarily due to pixels between -45 and $-30 \mathrm{HU}$ being counted as fat tissue. Hence, we conclude that visceral fat measurements derived using different fat HU ranges cannot be directly compared.

Outlier investigation showed that reliability of both VFA and VFRA measurements are strongly dependent upon breath cycle; individuals whose paired scans demonstrated large differences in lung inflation also demonstrated large differences in VFA and/or VFRA, particularly in the thoracic region. Caution should be exercised when using visceral fat measurements from the thoracic region as these measurements will be strongly affected by the amount of air held in the lungs at the time of the scan.

This study has important limitations. Our cohort may not be nationally or globally representative, though it is not specific to a particular race or ethnicity. These reference values have not been tested against clinical outcomes and were computed from kidney donor CT protocols only; we did not evaluate the effect of different $\mathrm{kVp}, \mathrm{mA}$, convolution kernel, contrast dosage, and/or slice thicknesses used in other protocols nor did we evaluate the effect of various disease states, height, or BMI on these measurements. Because we used retrospective scans, we could not control the slice thickness used in each scan and slice thickness was correlated with the type of scan due to scan protocols used. The vast majority of non-contrast scans used $5 \mathrm{~mm}$ slice thickness whereas the majority of contrast scans used $2.5 \mathrm{~mm}$ or smaller slice thickness, resulting in 'sharper' contrast images and 'blurrier' noncontrast images. The effect of this difference was not specifically addressed in this manuscript, though visual inspection of distributions showed no large, obvious deviations. 


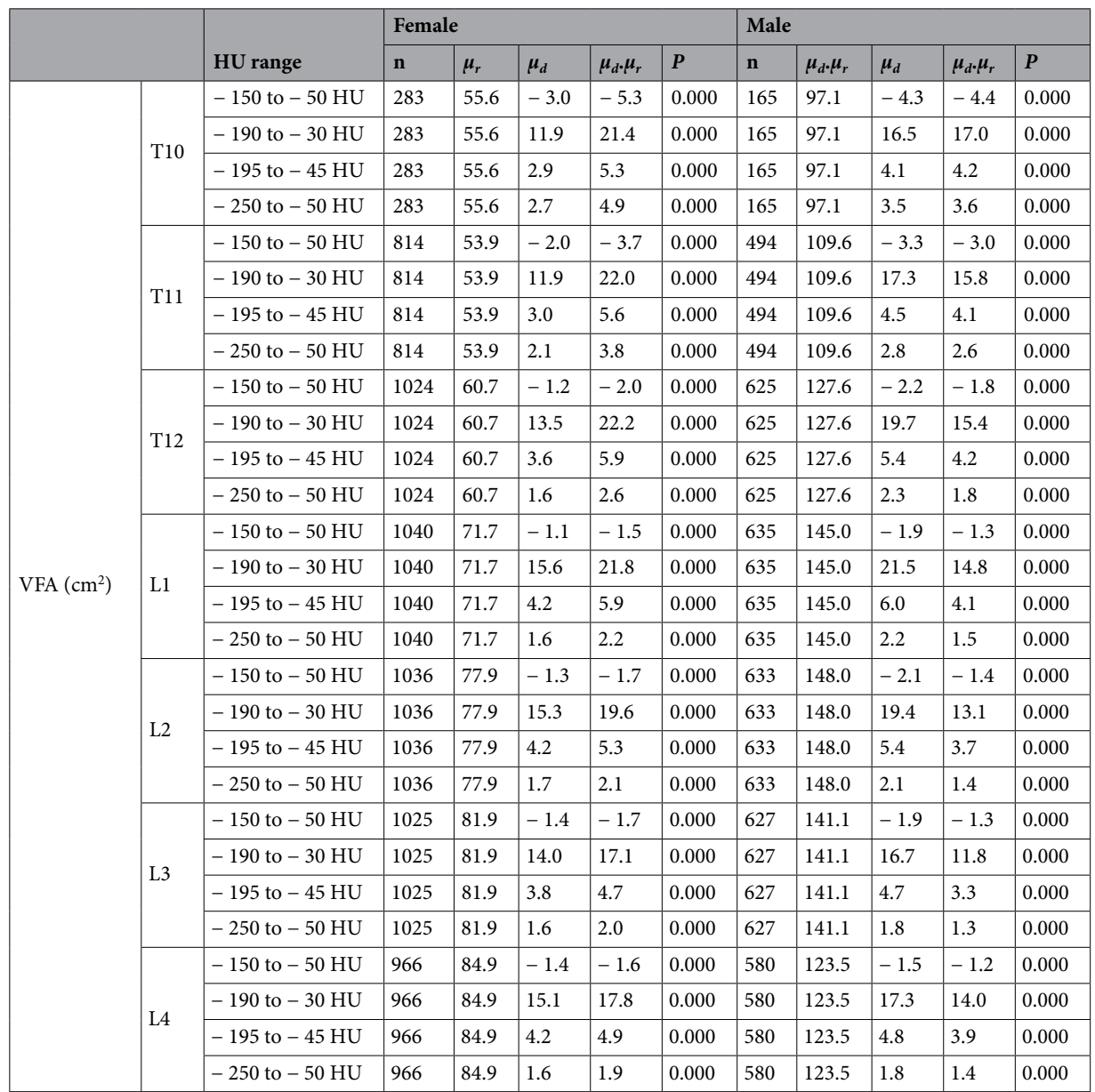

Table 6. Non-contrast scan mean VFA paired differences (comparison range-reference range) raw $\left(\mu_{d}\right)$ and as percent of overall mean reference range value $\left(\mu_{r}\right) . P$-values from paired t-test for T10-L4 with null hypothesis $\mu_{d}=0$. Negative values indicate comparison range value lower than reference range value, on average. Reference range is -205 to -51 HU. $P$-values $<0.01$ in bold.

Clinical CT scans obtained in the normal course of patient care can potentially be used for detailed crosssectional visceral fat evaluation. However, scans may not include vertebral levels for which reference values have been defined (e.g., L3) and may or may not use contrast enhancement. Furthermore, we have shown that the fat $\mathrm{HU}$ range used to identify fat pixels can significantly change the resulting measurements, rendering it perhaps one of the most important choices made in CT fat measurement. We report healthy population reference values for a wide range of vertebral levels, in both contrast and non-contrast phases, and using multiple different fat HU ranges. These values provide strong evidence towards standardizing visceral fat area and radiation attenuation measurements and provide a healthy reference population for other studies to compare against.

\section{Methods}

Study cohort. We retrospectively studied persons who underwent CT scans at Michigan Medicine as part of evaluation for kidney donation between 1999 and 2017. We have previously studied a subset of these kidney donor candidates as a healthy reference population for skeletal muscle ${ }^{25}$.

Patient age, sex, height, and weight were obtained from their medical record proximal to the date of evaluation for kidney donation, and the month and year of the evaluation appointment was recorded ${ }^{27}$. Candidates were included if they had a CT scan performed as part of evaluation for kidney donation, were deemed healthy enough to donate, had age, sex, height, and weight recorded in their electronic medical record, had both contrastenhanced and non-contrast-enhanced series available, and had a fascia boundary that was fully visible in the display field of view. 


\begin{tabular}{|c|c|c|c|c|c|c|c|c|c|c|c|c|}
\hline & \multirow[b]{2}{*}{ HU range } & \multicolumn{5}{|c|}{ Female } & \multicolumn{5}{|c|}{ Male } \\
\hline & & & $\mathrm{n}$ & $\mu_{r}$ & $\mu_{d}$ & $\mu_{d} /\left|\mu_{r}\right|(\%)$ & $P$ & $\mathbf{n}$ & $\mu_{r}$ & $\mu_{d}$ & $\mu_{d} /\left|\mu_{r}\right|(\%)$ & $P$ \\
\hline \multirow{28}{*}{$\begin{array}{l}\text { VFRA } \\
(H U)\end{array}$} & \multirow{4}{*}{$\mathrm{T} 10$} & -150 to $-50 \mathrm{HU}$ & 283 & -97.0 & 6.2 & 6.3 & 0.000 & 165 & -99.9 & 5.2 & 5.2 & 0.000 \\
\hline & & -190 to $-30 \mathrm{HU}$ & 283 & -97.0 & 12.2 & 12.6 & 0.000 & 165 & -99.9 & 10.1 & 10.1 & 0.000 \\
\hline & & -195 to $-45 \mathrm{HU}$ & 283 & -97.0 & 4.0 & 4.1 & 0.000 & 165 & -99.9 & 3.2 & 3.2 & 0.000 \\
\hline & & -250 to $-50 \mathrm{HU}$ & 283 & -97.0 & -4.0 & -4.1 & 0.000 & 165 & -99.9 & -2.8 & -2.8 & 0.000 \\
\hline & \multirow{4}{*}{ T11 } & -150 to $-50 \mathrm{HU}$ & 814 & -94.7 & 5.0 & 5.2 & 0.000 & 494 & -98.3 & 4.4 & 4.5 & 0.000 \\
\hline & & -190 to $-30 \mathrm{HU}$ & 814 & -94.7 & 11.6 & 12.3 & 0.000 & 494 & -98.3 & 9.6 & 9.7 & 0.000 \\
\hline & & -195 to $-45 \mathrm{HU}$ & 814 & -94.7 & 3.7 & 3.9 & 0.000 & 494 & -98.3 & 3.0 & 3.0 & 0.000 \\
\hline & & -250 to $-50 \mathrm{HU}$ & 814 & -94.7 & -3.0 & -3.1 & 0.000 & 494 & -98.3 & -2.1 & -2.1 & 0.000 \\
\hline & \multirow{4}{*}{ T12 } & -150 to $-50 \mathrm{HU}$ & 1024 & -92.4 & 3.8 & 4.1 & 0.000 & 625 & -96.2 & 3.5 & 3.7 & 0.000 \\
\hline & & -190 to $-30 \mathrm{HU}$ & 1024 & -92.4 & 11.1 & 12.0 & 0.000 & 625 & -96.2 & 9.0 & 9.4 & 0.000 \\
\hline & & -195 to $-45 \mathrm{HU}$ & 1024 & -92.4 & 3.5 & 3.7 & 0.000 & 625 & -96.2 & 2.8 & 2.9 & 0.000 \\
\hline & & -250 to $-50 \mathrm{HU}$ & 1024 & -92.4 & -1.8 & -2.0 & 0.000 & 625 & -96.2 & -1.3 & -1.3 & 0.000 \\
\hline & \multirow{4}{*}{ L1 } & -150 to $-50 \mathrm{HU}$ & 1040 & -92.2 & 3.4 & 3.7 & 0.000 & 635 & -95.5 & 3.0 & 3.1 & 0.000 \\
\hline & & -190 to $-30 \mathrm{HU}$ & 1040 & -92.2 & 10.5 & 11.4 & 0.000 & 635 & -95.5 & 8.4 & 8.8 & 0.000 \\
\hline & & -195 to $-45 \mathrm{HU}$ & 1040 & -92.2 & 3.3 & 3.6 & 0.000 & 635 & -95.5 & 2.6 & 2.7 & 0.000 \\
\hline & & -250 to $-50 \mathrm{HU}$ & 1040 & -92.2 & -1.4 & -1.5 & 0.000 & 635 & -95.5 & -0.9 & -0.9 & 0.000 \\
\hline & \multirow{4}{*}{ L2 } & -150 to $-50 \mathrm{HU}$ & 1036 & -93.4 & 3.5 & 3.7 & 0.000 & 633 & -96.6 & 2.9 & 3.0 & 0.000 \\
\hline & & -190 to $-30 \mathrm{HU}$ & 1036 & -93.4 & 10.1 & 10.8 & 0.000 & 633 & -96.6 & 7.9 & 8.2 & 0.000 \\
\hline & & -195 to $-45 \mathrm{HU}$ & 1036 & -93.4 & 3.1 & 3.4 & 0.000 & 633 & -96.6 & 2.4 & 2.5 & 0.000 \\
\hline & & -250 to $-50 \mathrm{HU}$ & 1036 & -93.4 & -1.4 & -1.5 & 0.000 & 633 & -96.6 & -0.9 & -0.9 & 0.000 \\
\hline & \multirow{4}{*}{ L3 } & -150 to $-50 \mathrm{HU}$ & 1025 & -94.8 & 3.5 & 3.7 & 0.000 & 627 & -97.8 & 2.8 & 2.9 & 0.000 \\
\hline & & -190 to $-30 \mathrm{HU}$ & 1025 & -94.8 & 9.5 & 10.0 & 0.000 & 627 & -97.8 & 7.5 & 7.6 & 0.000 \\
\hline & & -195 to $-45 \mathrm{HU}$ & 1025 & -94.8 & 3.0 & 3.1 & 0.000 & 627 & -97.8 & 2.3 & 2.3 & 0.000 \\
\hline & & -250 to $-50 \mathrm{HU}$ & 1025 & -94.8 & -1.4 & -1.5 & 0.000 & 627 & -97.8 & -0.8 & -0.9 & 0.000 \\
\hline & \multirow{4}{*}{ L4 } & -150 to $-50 \mathrm{HU}$ & 966 & -95.3 & 3.3 & 3.4 & 0.000 & 580 & -96.7 & 2.5 & 2.6 & 0.000 \\
\hline & & -190 to $-30 \mathrm{HU}$ & 966 & -95.3 & 9.3 & 9.8 & 0.000 & 580 & -96.7 & 7.7 & 8.0 & 0.000 \\
\hline & & -195 to $-45 \mathrm{HU}$ & 966 & -95.3 & 2.9 & 3.0 & 0.000 & 580 & -96.7 & 2.3 & 2.4 & 0.000 \\
\hline & & -250 to $-50 \mathrm{HU}$ & 966 & -95.3 & -1.2 & -1.2 & 0.000 & 580 & -96.7 & -0.7 & -0.7 & 0.000 \\
\hline
\end{tabular}

Table 7. Contrast scan mean VFRA paired differences (comparison range-reference range) raw $\left(\mu_{d}\right)$ and as percent of absolute overall mean reference range value $\left(\mu_{d} /\left|\mu_{r}\right|\right)$. $P$ - values from paired t-test for T10-L4 with null hypothesis $\mu_{d}=0$. Negative values indicate comparison range value lower than reference range value, on average. Reference range is -205 to -51 HU. $P$-values $<0.01$ in bold.

Body mass index (BMI) was computed and categorized into groups according the World Health Organization International Classification standard ${ }^{28}$. Race, unavailable for $25 \%$ of the cohort, was reported but not specifically analyzed.

CT imaging was extracted for 2,902 total donor candidates between the ages of 18 and 75. The $n=1,677$ candidates of all ages having both a contrast and non-contrast series scan were used in this analysis.

All candidates included in the analysis were scanned using the GE 'Standard' reconstruction algorithm (which is optimized for visualizing soft tissue) at $120 \mathrm{kVp}$ in a Discovery or LightSpeed scanner. Non-contrast scans used 2.5 (2007-2010), 3.75 (2008), or $5 \mathrm{~mm}$ (1999-2017) slice thickness and contrast scans used 0.625 (2005-2010), 1.25 (2002-2008), 2.5 (1999-2002, 2010-2017), 3.75 (1999), and $5 \mathrm{~mm}$ (2002-2016) slice thickness. Tube current was automatically modulated in proportion to body mass.

CT image processing. After being transferred into a spatial database, CT images were processed using Analytic Morphomics, a semi-automated image analysis method that has been previously described ${ }^{24,29,30}$. A combination of automated and user-guided algorithms written in Matlab (The Mathworks Inc, Natick, MA) identified the vertebral bodies to serve as an anatomical coordinate reference system. Next, the outer abdominal fascia and skin boundary were identified at all available vertebral levels to create enclosed regions of interest, which were confirmed by multiple trained researchers (Fig. 4). 


\begin{tabular}{|c|c|c|c|c|c|c|c|c|c|c|c|c|}
\hline & \multirow[b]{2}{*}{ HU range } & \multicolumn{5}{|c|}{ Female } & \multicolumn{5}{|c|}{ Male } \\
\hline & & & $\mathbf{n}$ & $\mu_{r}$ & $\mu_{d}$ & $\mu_{d} /\left|\mu_{r}\right|(\%)$ & $P$ & $\mathbf{n}$ & $\mu_{r}$ & $\mu_{d}$ & $\mu_{d} /\left|\mu_{r}\right|(\%)$ & $P$ \\
\hline \multirow{28}{*}{$\begin{array}{l}\text { VFRA } \\
(H U)\end{array}$} & \multirow{4}{*}{$\mathrm{T} 10$} & -150 to $-50 \mathrm{HU}$ & 283 & -98.1 & 7.4 & 7.5 & 0.000 & 165 & -101.0 & 6.3 & 6.3 & 0.000 \\
\hline & & -190 to $-30 \mathrm{HU}$ & 283 & -98.1 & 13.3 & 13.6 & 0.000 & 165 & -101.0 & 11.8 & 11.7 & 0.000 \\
\hline & & -195 to $-45 \mathrm{HU}$ & 283 & -98.1 & 4.5 & 4.5 & 0.000 & 165 & -101.0 & 3.9 & 3.8 & 0.000 \\
\hline & & -250 to $-50 \mathrm{HU}$ & 283 & -98.1 & -5.7 & -5.9 & 0.000 & 165 & -101.0 & -4.6 & -4.5 & 0.000 \\
\hline & \multirow{4}{*}{ T11 } & -150 to $-50 \mathrm{HU}$ & 814 & -96.0 & 6.4 & 6.6 & 0.000 & 494 & -98.8 & 5.0 & 5.0 & 0.000 \\
\hline & & -190 to $-30 \mathrm{HU}$ & 814 & -96.0 & 13.1 & 13.6 & 0.000 & 494 & -98.8 & 10.7 & 10.9 & 0.000 \\
\hline & & -195 to $-45 \mathrm{HU}$ & 814 & -96.0 & 4.3 & 4.5 & 0.000 & 494 & -98.8 & 3.4 & 3.5 & 0.000 \\
\hline & & -250 to $-50 \mathrm{HU}$ & 814 & -96.0 & -4.8 & -5.0 & 0.000 & 494 & -98.8 & -3.4 & -3.5 & 0.000 \\
\hline & \multirow{4}{*}{$\mathrm{T} 12$} & -150 to $-50 \mathrm{HU}$ & 1024 & -92.8 & 4.6 & 5.0 & 0.000 & 625 & -95.9 & 3.6 & 3.7 & 0.000 \\
\hline & & -190 to $-30 \mathrm{HU}$ & 1024 & -92.8 & 12.5 & 13.4 & 0.000 & 625 & -95.9 & 9.9 & 10.4 & 0.000 \\
\hline & & -195 to $-45 \mathrm{HU}$ & 1024 & -92.8 & 3.9 & 4.2 & 0.000 & 625 & -95.9 & 3.1 & 3.2 & 0.000 \\
\hline & & -250 to $-50 \mathrm{HU}$ & 1024 & -92.8 & -3.1 & -3.3 & 0.000 & 625 & -95.9 & -2.1 & -2.2 & 0.000 \\
\hline & \multirow{4}{*}{ L1 } & -150 to $-50 \mathrm{HU}$ & 1040 & -90.8 & 3.5 & 3.8 & 0.000 & 635 & -94.3 & 2.7 & 2.8 & 0.000 \\
\hline & & -190 to $-30 \mathrm{HU}$ & 1040 & -90.8 & 11.6 & 12.8 & 0.000 & 635 & -94.3 & 9.1 & 9.7 & 0.000 \\
\hline & & -195 to $-45 \mathrm{HU}$ & 1040 & -90.8 & 3.6 & 3.9 & 0.000 & 635 & -94.3 & 2.8 & 3.0 & 0.000 \\
\hline & & -250 to $-50 \mathrm{HU}$ & 1040 & -90.8 & -2.0 & -2.2 & 0.000 & 635 & -94.3 & -1.4 & -1.4 & 0.000 \\
\hline & \multirow{4}{*}{$\mathrm{L} 2$} & -150 to $-50 \mathrm{HU}$ & 1036 & -91.9 & 3.5 & 3.8 & 0.000 & 633 & -95.4 & 2.6 & 2.7 & 0.000 \\
\hline & & -190 to $-30 \mathrm{HU}$ & 1036 & -91.9 & 11.0 & 12.0 & 0.000 & 633 & -95.4 & 8.6 & 9.0 & 0.000 \\
\hline & & -195 to $-45 \mathrm{HU}$ & 1036 & -91.9 & 3.4 & 3.7 & 0.000 & 633 & -95.4 & 2.6 & 2.7 & 0.000 \\
\hline & & -250 to $-50 \mathrm{HU}$ & 1036 & -91.9 & -2.0 & -2.1 & 0.000 & 633 & -95.4 & -1.3 & -1.3 & 0.000 \\
\hline & \multirow{4}{*}{ L3 } & -150 to $-50 \mathrm{HU}$ & 1025 & -93.5 & 3.4 & 3.6 & 0.000 & 627 & -96.5 & 2.4 & 2.5 & 0.000 \\
\hline & & -190 to $-30 \mathrm{HU}$ & 1025 & -93.5 & 10.2 & 10.9 & 0.000 & 627 & -96.5 & 7.9 & 8.2 & 0.000 \\
\hline & & -195 to $-45 \mathrm{HU}$ & 1025 & -93.5 & 3.2 & 3.4 & 0.000 & 627 & -96.5 & 2.4 & 2.5 & 0.000 \\
\hline & & -250 to $-50 \mathrm{HU}$ & 1025 & -93.5 & -1.9 & -2.1 & 0.000 & 627 & -96.5 & -1.2 & -1.2 & 0.000 \\
\hline & \multirow{4}{*}{ L4 } & -150 to $-50 \mathrm{HU}$ & 966 & -93.8 & 3.1 & 3.3 & 0.000 & 580 & -95.2 & 2.3 & 2.4 & 0.000 \\
\hline & & -190 to $-30 \mathrm{HU}$ & 966 & -93.8 & 10.0 & 10.6 & 0.000 & 580 & -95.2 & 8.3 & 8.7 & 0.000 \\
\hline & & -195 to $-45 \mathrm{HU}$ & 966 & -93.8 & 3.1 & 3.3 & 0.000 & 580 & -95.2 & 2.5 & 2.6 & 0.000 \\
\hline & & -250 to $-50 \mathrm{HU}$ & 966 & -93.8 & -1.6 & -1.7 & 0.000 & 580 & -95.2 & -1.1 & -1.1 & 0.000 \\
\hline
\end{tabular}

Table 8. Non-contrast scan mean VFRA paired differences (comparison range-reference range) raw $\left(\mu_{d}\right)$ and as percent of absolute overall mean reference range value $\left(\mu_{d} /\left|\mu_{r}\right|\right)$. $P$-values from paired t-test for T10-L4 with null hypothesis $\mu_{d}=0$. Negative values indicate comparison range value lower than reference range value, on average. Reference range is -205 to $-51 \mathrm{HU}$. $P$-values $<0.01$ in bold.

Measurements were taken at each vertebral level between T10 through L4. Sample size at each vertebra level varied due to differences in anatomy included in each subject's scan. Vertebra levels that did not include both a non-contrast and contrast measurement were excluded.

Fat measurements were computed using the axial slice nearest the inferior aspect of each vertebral body. Visceral fat area (VFA) was computed as the total area of pixels enclosed by the outer abdominal fascia, falling within five different fat Hounsfield Unit (HU) ranges: (1) - 205 to - $51 \mathrm{HU}$ (our reference), (2) - 150 to - 50, (3) -195 to -45 , (4) -190 to $-30,(5)-250$ to -50 HU. Mean radiation attenuation (VFRA) was computed as the mean HU of all pixels included in VFA.

Statistical methods. Male and female demographics, CT parameters, and fat measurements are shown separately as mean $+/-$ s.d. for continuous variables and proportion for categorical variables. Continuous means were compared using two-tailed t-tests assuming unequal variance and categorical proportions were compared using the Chi-squared test. 

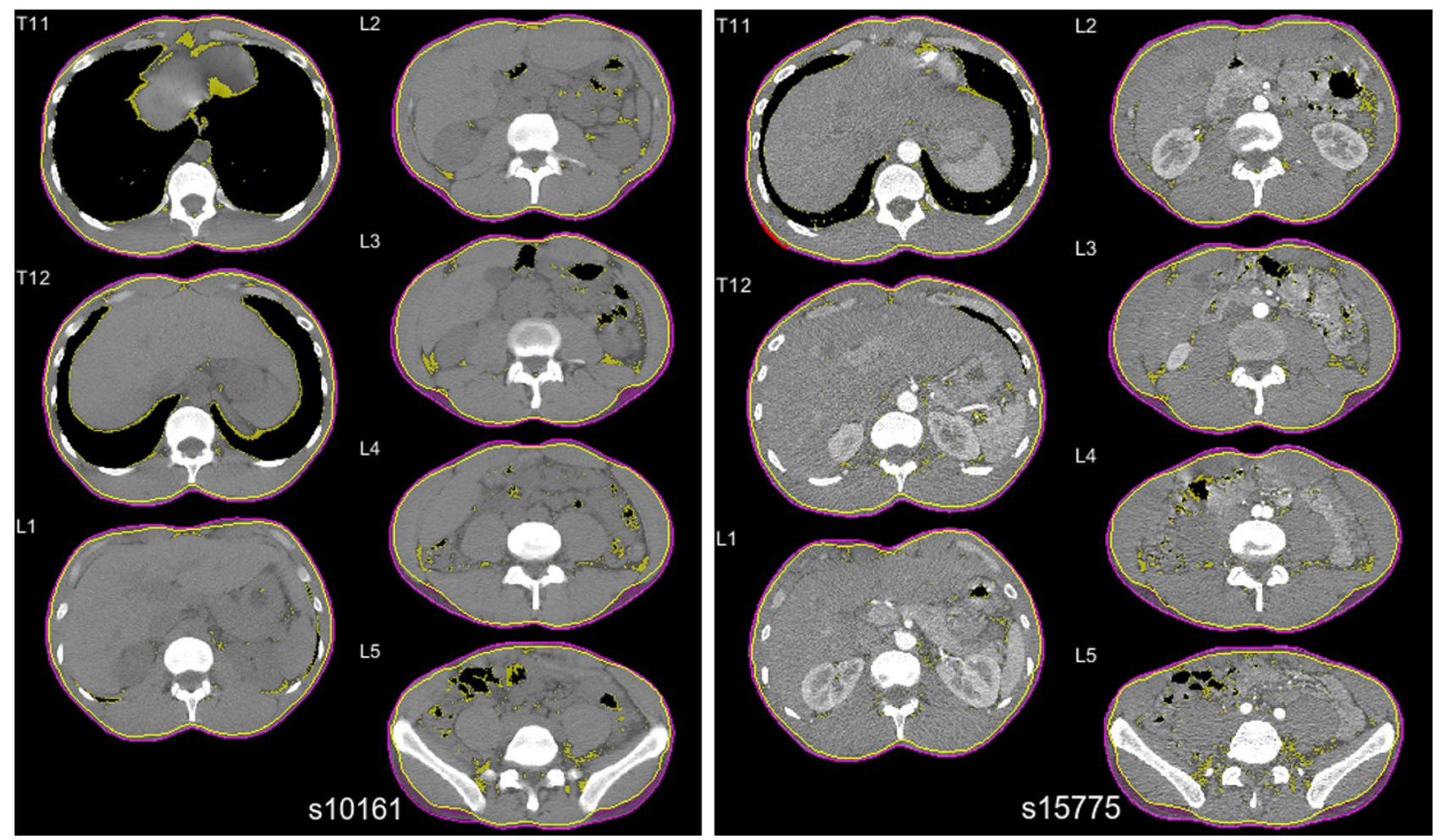

Figure 3. Example of healthy 36 y/o male non-contrast (left) and contrast (right) CT axial slices, showing T11-L5 visceral fat area (yellow-shaded region), subcutaneous fat area (purple shaded region), outer abdominal fascia boundary (yellow line), and skin boundary (purple line). Images demonstrate different lung inflation between contrast and non-contrast scans and resulting shift in organ and fat pixels.

The within-subject difference between (1) enhanced and non-enhanced fat measures, and (2) between each $\mathrm{HU}$ range and the reference range were assessed using paired t-tests. The mean difference and the mean difference expressed as a percentage of the (1) enhanced and (2) reference measurement are reported for each test. Fat HU ranges were analyzed separately in enhanced and non-enhanced scans.

Bland-Altman plots were used to visualize the agreement between pairs of measurements ${ }^{31}$.

The sex-specific mean and standard deviation of each fat measure were calculated independently for vertebral levels from T10 to L4.

An alpha level of .01 was used to determine statistical significance. All statistical tests were performed in $\mathrm{R}$ version $4.0 .2^{32}$, using the package 'ggplot $2^{\text {'33 }}$ for data visualization.

Ethical approval and informed consent. This study was approved by the Institutional Review Board of Michigan Medicine. All methods were performed in accordance with the relevant guidelines and regulations of the United States. Because existing CT scans were used retrospectively, the requirement for informed consent was waived by the Institutional Review Board of the University of Michigan. 

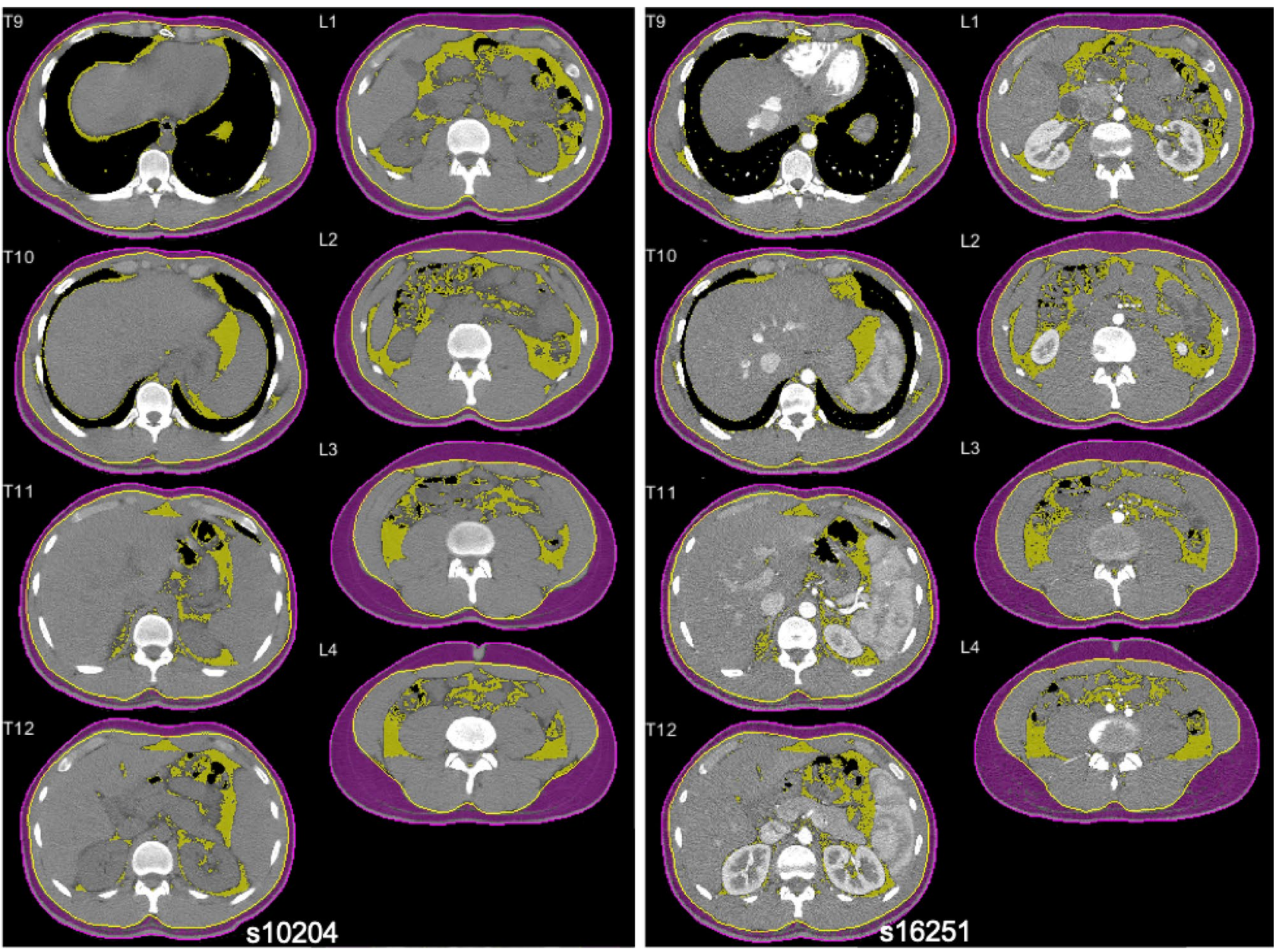

Figure 4. Example of healthy 20 y/o male non-contrast (left) and contrast (right) CT axial slices, showing T10-L4 visceral fat area (yellow-shaded region), subcutaneous fat area (purple shaded region), outer abdominal fascia boundary (yellow line), and skin boundary (purple line). Portions of skin boundary that are coincident with the scan field of view are highlighted in red.

\section{Data availability}

The datasets generated during and/or analyzed during the current study are available from the corresponding author upon reasonable request.

Received: 7 May 2021; Accepted: 24 January 2022

Published online: 11 February 2022

\section{References}

1. Pickhardt, P. J. et al. Utilizing fully automated abdominal ct-based biomarkers for opportunistic screening for metabolic syndrome in adults without symptoms. Am. J. Roentgenol. 216, 85-92 (2021).

2. Lee, J. J. et al. Cross-sectional associations of computed tomography (ct)-derived adipose tissue density and adipokines: the framingham heart study. J. Am. Heart Assoc. 5, e002545 (2016).

3. Shah, R. V. et al. Visceral adiposity and the risk of metabolic syndrome across body mass index: the mesa study. JACC Cardiovasc. Imaging 7, 1221-1235 (2014)

4. Lee, J. J., Pedley, A., Hoffmann, U., Massaro, J. M. \& Fox, C. S. Association of changes in abdominal fat quantity and quality with incident cardiovascular disease risk factors. J. Am. Coll. Cardiol. 68, 1509-1521 (2016).

5. Lee, J. J., Yin, X., Hoffmann, U., Fox, C. S. \& Benjamin, E. J. Relation of pericardial fat, intrathoracic fat, and abdominal visceral fat with incident atrial fibrillation (from the framingham heart study). Am. J. Cardiol. 118, 1486-1492 (2016).

6. Tapper, E. B. et al. Body composition predicts mortality and decompensation in compensated cirrhosis patients: a prospective cohort study. JHEP Rep. 2, 100061 (2020).

7. Parikh, N. D. et al. Body composition predicts survival in patients with hepatocellular carcinoma treated with transarterial chemoembolization. Cancer Res. Treat. Off. J. Korean Cancer Assoc. 50, 530 (2018).

8. Ebadi, M. et al. Visceral adipose tissue radiodensity is linked to prognosis in hepatocellular carcinoma patients treated with selective internal radiation therapy. Cancers 12, 356 (2020).

9. Vehmas, T., Kairemo, K. \& Taavitsainen, M. Measuring visceral adipose tissue content from contrast enhanced computed tomography. Int. J. Obes. Relat. Metab. Disord. J. Int. Assoc. Study Obes. 20, 570-573 (1996).

10. Rollins, K. E. et al. Body composition measurement using computed tomography: does the phase of the scan matter?. Nutrition 41, 37-44 (2017) 
11. Paris, M. T. et al. Influence of contrast administration on computed tomography-based analysis of visceral adipose and skeletal muscle tissue in clear cell renal cell carcinoma. J. Parenter. Enteral Nutr. 42, 1148-1155 (2018).

12. Perez, A. A., Pickhardt, P. J., Elton, D. C., Sandfort, V. \& Summers, R. M. Fully automated ct imaging biomarkers of bone, muscle, and fat: correcting for the effect of intravenous contrast. Abdom. Radiol. 46, 1229-1235 (2021).

13. Morsbach, F., Zhang, Y.-H., Martin, L., Lindqvist, C. \& Brismar, T. Body composition evaluation with computed tomography: Contrast media and slice thickness cause methodological errors. Nutrition 59, 50-55 (2019).

14. Gohmann, R. F. et al. 3d-segmentation and characterization of visceral and abdominal subcutaneous adipose tissue on ct: influence of contrast medium and contrast phase. Quant. Imaging Med. Surg. 11, 697 (2021).

15. Maurovich-Horvat, P. et al. Comparison of anthropometric, area-and volume-based assessment of abdominal subcutaneous and visceral adipose tissue volumes using multi-detector computed tomography. Int. J. Obes. 31, 500-506 (2007).

16. Balentine, C. J. et al. Validating quantitative obesity measurements in colorectal cancer patients. J. Surg. Res. 164, 18-22 (2010).

17. Kaess, B. et al. The ratio of visceral to subcutaneous fat, a metric of body fat distribution, is a unique correlate of cardiometabolic risk. Diabetologia 55, 2622-2630 (2012).

18. Kvist, H., Sjöström, L. \& Tylen, U. Adipose tissue volume determinations in women by computed tomography: technical considerations. Int. J. Obes. 10, 53-67 (1986).

19. Kvist, H., Chowdhury, B., Sjöström, L., Tylen, U. \& Cederblad, A. Adipose tissue volume determination in males by computed tomography and $40 \mathrm{k}$. Int. J. Obes. 12, 249-266 (1988).

20. Goodpaster, B. H., Kelley, D. E., Wing, R. R., Meier, A. \& Thaete, F. L. Effects of weight loss on regional fat distribution and insulin sensitivity in obesity. Diabetes 48, 839-847 (1999).

21. Wajchenberg, B. L. Subcutaneous and visceral adipose tissue: their relation to the metabolic syndrome. Endocr. Rev. 21, 697-738 (2000).

22. Borkan, G. A. et al. Assessment of abdominal fat content by computed tomography. Am. J. Clin. Nutr. 36, 172-177 (1982).

23. Shen, W. et al. Total body skeletal muscle and adipose tissue volumes: estimation from a single abdominal cross-sectional image. J. Appl. Physiol. (1985) 97, 2333-2338 (2004). https://www.ncbi.nlm.nih.gov/pubmed/15310748. https://doi.org/10.1152/japplphysi ol.00744.2004.

24. Derstine, B. A. et al. Quantifying sarcopenia reference values using lumbar and thoracic muscle areas in a healthy population. J. Nutr. Health Aging 1-6 (2017).

25. Derstine, B. A. et al. Skeletal muscle cutoff values for sarcopenia diagnosis using t10 to 15 measurements in a healthy us population. Sci. Rep. 8, 11369 (2018).

26. Werf, A. et al. Percentiles for skeletal muscle index, area and radiation attenuation based on computed tomography imaging in a healthy caucasian population. Eur. J. Clin. Nutr. 1 (2017).

27. Hanauer, D. A., Mei, Q., Law, J., Khanna, R. \& Zheng, K. Supporting information retrieval from electronic health records: A report of university of michigan's nine-year experience in developing and using the electronic medical record search engine (emerse). $J$. Biomed. Inform. 55, 290-300 (2015). https://www.ncbi.nlm.nih.gov/pubmed/25979153. https://doi.org/10.1016/j.jbi.2015.05.003.

28. Organization, W. H. Obesity: Preventing and Managing the Global Epidemic. 894 (World Health Organization, 2000).

29. Krishnamurthy, V. et al. Use of analytic morphomics of liver, spleen, and body composition to identify patients at risk for cirrhosis. Clin. Gastroenterol. Hepatol. 13, 360-368 e5 (2015). https://www.ncbi.nlm.nih.gov/pubmed/25083565. https://doi.org/10.1016/j. cgh.2014.07.042.

30. Holcombe, S. A. \& Wang, S. C. Subcutaneous Fat Distribution in the Human Torso. In IRCOBI Conference, IRC-14-43 (2014).

31. Bland, J. M. \& Altman, D. Statistical methods for assessing agreement between two methods of clinical measurement. The Lancet 327, 307-310 (1986)

32. R Core Team. R: A Language and Environment for Statistical Computing. (R Foundation for Statistical Computing, Vienna, Austria, 2016). https://www.R-project.org/.

33. Wickham, H. ggplot2: Elegant Graphics for Data Analysis (Springer, 2009). http://ggplot2.org.

\section{Author contributions}

B.D., S.H., G.S., and S.W. designed the study. N.W. and S.H. developed the Analytic Morphomics processing code. B.D. and B.R. performed CT processing. B.D. performed the data analyses. B.D. and G.S. collected and interpreted the data and wrote the manuscript. All authors reviewed the manuscript.

\section{Competing interests}

Brian A Derstine, Brian E Ross, Nicholas C Wang, and Grace L Su declare that they have no conflict of interest. Sven A Holcombe and Stewart C Wang are listed as inventors on a US Patent for Analytic Morphomics (\#US $20140064583 \mathrm{A1})$.

\section{Additional information}

Correspondence and requests for materials should be addressed to B.A.D.

Reprints and permissions information is available at www.nature.com/reprints.

Publisher's note Springer Nature remains neutral with regard to jurisdictional claims in published maps and institutional affiliations.

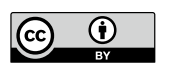

Open Access This article is licensed under a Creative Commons Attribution 4.0 International License, which permits use, sharing, adaptation, distribution and reproduction in any medium or format, as long as you give appropriate credit to the original author(s) and the source, provide a link to the Creative Commons licence, and indicate if changes were made. The images or other third party material in this article are included in the article's Creative Commons licence, unless indicated otherwise in a credit line to the material. If material is not included in the article's Creative Commons licence and your intended use is not permitted by statutory regulation or exceeds the permitted use, you will need to obtain permission directly from the copyright holder. To view a copy of this licence, visit http://creativecommons.org/licenses/by/4.0/.

(C) The Author(s) 2022 